\title{
Depression and Dementia in Elderly People
}

\author{
Gjon Preci ${ }^{1}$, lliriana Zekja ${ }^{2,3} \mathbb{D}$, Jera Kruja ${ }^{3}$, Erjona Abazaj ${ }^{2 *}$ (D) \\ ${ }^{1}$ Community Mental Health Cente, Shkodra, Albania; ${ }^{2}$ Faculty of Medical Science and Technology, Tirana, Albania; ${ }^{3}$ Hospital \\ Center "Mother Teresa" Tirana, Tirana, Albania
}

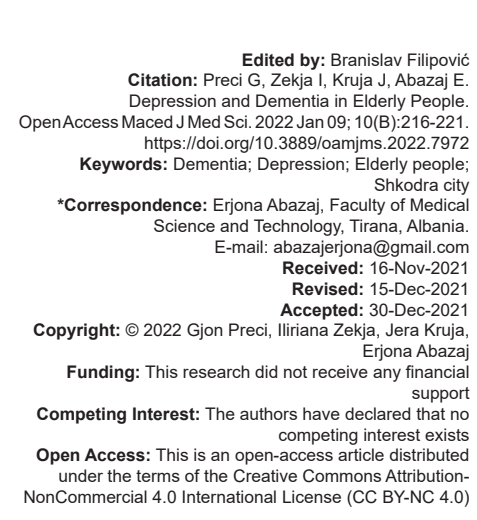

Introduction

Neuropsychiatric diseases are a leading cause of disability worldwide, with numbers expected to increase dramatically in the coming decades, mainly due to aging populations [1]. Medically proven the most incapacitating of these illnesses is dementia causing substantial physical and psychological disability, suffering, dependency, and economic costs for patients, caregivers, and society alike [2].

Dementia and depression are mental health problems that are commonly encountered in neuropsychiatric practice in the elderly [3]. Patients with dementia of any type have a high incidence of major depression. Depression is a frequent additional problem among people with dementia, and one that can greatly diminish quality of life for both patient and care partner. Depression is especially common in people with vascular dementia but also affects many with Alzheimer's disease [4], [5]. The occurrence of a first major depressive episode in an older adult is a risk factor for developing dementia [6].

The majority of people living with dementia worldwide in 2015 was estimated at 47.47 million, reaching 75.63 million in 2030 and 135.46 million in 2050 [2]. On the flip side, approximately half of the patients with late-onset depression have cognitive impairment. The prevalence of depression in dementias has been reported to be between 9 and $68 \%$ [3].

Depression and dementia are closely related. However, the relationship is complex and the mechanism linking remains unknown; depression can coexist with dementia or can also be confused with dementia, hence, the importance of a differential diagnosis [7]. Furthermore, it was found that dementia affects performance in everyday life to produce total disability [8]. The aim of this study is to determine the prevalence depression in elderly people with dementia and to assess the association between them and risk factors. 


\section{Methods}

\section{Study area}

Shkodër is the fifth most populous city of the Republic of Albania and the seat of Shkodër County and Shkodër Municipality. It is located in the northern region of country. Shkodër is affected by a seasonal Mediterranean climate with continental influences. As of the 2011 census, the municipal unit of Shkodër had an estimated population of 77,075 of whom 37,630 were men and 39,445 women.

\section{Study design and data collection}

This is a cross-sectional study associating dementia with depression among the population from 50 until to more than 85 years old for a period of 4 years. The community center of mental health of Shkodra district serves as a center for the diagnose, treats and management of all cases with mental health problem. As a result, during the 4 years, about 187 patients with dementia aged 50 years and above are selected using the cluster sampling method. All patients were evaluated by the medical staff of the community center for their mental health problems. Patients were considered to have depression when one or more ICD codes for depression were recorded as primary or secondary diagnosis. The inclusion criteria were all patients age 50 years old and above diagnose with dementia. Exclusion criteria were all patients with other mental health problem except dementia and depression and patients $<50$ years old.

The information regarding all patients remains anonymous in this research. As they were recruited to the population survey related and to the severity of the dementia or depression, the patients or their familiar signed a consent themselves or through their informant. The procedure for analyzed patients and collection of data was approved by the local ethics committees.

\section{Data analysis}

The data are presented as mean and percentage. The Kolmogorov-Smirnov test was used to test the data for normal distribution. Multiple regression analysis was used to identify factors predicting severity of depression. The software Statistical Package for the Social Sciences version 20.0 was used for data calculation. $p<0.05$ was taken as statistically significant.

\section{Results}

According to this study, a number of 187 patients with dementia are enrolled for a period of 4 years. The presence of dementia by the medical staff of the Community Center of Mental Health of Shkodra district was determined by Mini-Mental State Examination. Evidentially, the minimum age resulted as 50 and maximum 89 years old with average $75 \pm 8.1 \mathrm{std}$. The Beck Depression Inventory was used to assess depression among dementia patients. Patients were considered to have depression when one or more ICD codes for depression were recorded as primary or secondary diagnosis. The prevalence of depression among those patients with dementia resulted $44.9 \%$ (84/187).

The baseline characteristics of the study population is presented in detail in Table 1. Male with dementia was the most predominant sex compared to female with percentage $60.4 \%$ and $39.6 \%$, respectively. In conclusion, depression was being found more predominant to female patients with dementia.

Regarding the age groups, the age over 70 years old presented a high number of patients with dementia and depression also. The age group of 50-59 years old presents a low number of patients $1.6 \%$ with dementia and $1.2 \%$ with depression. Those who determined the age group of 60-69 years old presented a percentage $4.8 \%$ for dementia and $5.9 \%$ for depression. Concerning the age group of 70-79 years presented $31.3 \%$ of patients in dementia and $38.1 \%$ with depression, those over 80 years old presented the highest number with dementia $62.6 \%$ and for those with depression in $54.8 \%$ of dementia patients (Table 1 ).

Some of risk factors (such as type of residence, marital status, lifestyle and education level) that influence in dementia and depression are included in this study. Analytically was seen that a high number of patients with dementia $67.4 \%(126 / 187)$ and depression $54.8 \%$ $(46 / 84)$ lived in urban area. Patients with dementia that referred single related to marital status resulted $2.7 \%$ and those with depression resulted $10.7 \%$. Those who

Table 1: Baseline characteristics of the study population

\begin{tabular}{lll}
\hline Variables & $\begin{array}{l}\text { Dementia } \\
\text { patients, No. (\%) }\end{array}$ & $\begin{array}{l}\text { Depression } \\
\text { patients, No. (\%) }\end{array}$ \\
\hline Gender & 187 & 84 \\
Women & $74(39.6)$ & $45(53.6)$ \\
Man & $113(60.4)$ & $39(46.4)$ \\
Age (years) & & \\
$50-59$ & $3(1.6)$ & $1(1.2)$ \\
$60-69$ & $9(4.8)$ & $5(5.9)$ \\
$70-79$ & $58(31.0)$ & $32(38.1)$ \\
$\geq 80$ & $117(62.6)$ & $46(54.8)$ \\
Type of residence & $126(67.4)$ & $46(54.8)$ \\
Urban & $61(32.6)$ & $38(45.2)$ \\
Rural & & \\
Marital status & $5(2.7)$ & $2(2.4)$ \\
Single & $108(57.7)$ & $42(50)$ \\
Married & $25(13.4)$ & $17(20.2)$ \\
Divorced & $49(26.2)$ & $22(16.2)$ \\
Widow & & \\
Lifestyle & $139(74.3)$ & $49(58.3)$ \\
Living with family & $48(25.7)$ & $35(41.7)$ \\
Living alone & & $9(10.7)$ \\
Education level & $15(8.0)$ & $22(26.2)$ \\
Illiterate & $39(20.8)$ & $39(46.4)$ \\
Elementary and & & $14(16.7)$ \\
$\quad$ Secondary & $103(55.1)$ & \\
High school & $30(16.1)$ & \\
University & & \\
\hline
\end{tabular}


were married turned out $57.7 \%$ and with depression $50 \%$, while divorced with dementia $13.4 \%$ and with depression $20.2 \%$, and window resulted $26.2 \%$ for those with dementia and $16.2 \%$ within those with depression.

Most of them living with their family $74.3 \%$ for those with dementia and $58.3 \%$ for those with depression. Education level presents a diversity of case distribution, so, patients in illiterate resulted $8.2 \%$ in dementia and $10.7 \%$ in depression, those with elementary and secondary level resulted $20.8 \%$ in dementia and $26.2 \%$ in depression. The high school level referred $55.1 \%$ of patients with dementia and $46.4 \%$ of patients with depression, and with university academic level referred almost the same percentage $16.1 \%$ of patients with dementia and $16.7 \%$ of patients with depression.

The severity of dementia and depression in study population are presented in Figure 1. Related to severity of dementia, $17 \%(32 / 187)$ were in mild dementia, 48\% (89/187) in moderate dementia, and $35 \%(66 / 187)$ in severe dementia.

In relation to the severity of depression, most of the patients were in moderate depression 61\% (51/84), in severe depression were $28 \%$ (24/84) of patients, and others $11 \%$ (9/84) were in mild depression.

Based on several previous neurological research documents, there are over 100 diseases that may cause dementia. The most common causes of dementia include Alzheimer's disease, vascular dementia, and dementia with Lewy bodies. In this study, $31.5 \%$ of patients resulted with Alzheimer disease, vascular dementia $12.8 \%$, and Lewy body dementia (LBD) $10.2 \%$, and also, $45.5 \%$ of all patients were classified in unspecified cases (Table 2). Contrastingly, patients with depression appears to have a high prevalence of cases in type of unspecified cases and $A D$, followed by VD and LBD dementia type.

Table 2: Dementia type and distribution of types within the depression patients

\begin{tabular}{lll}
\hline Type of dementia & No. of patients & Percentage (Cl 95\%) \\
\hline Alzheimer's disease & 59 & $31.5(25.7-41.8)$ \\
Vascular dementia & 24 & $12.8(7.9-18.1)$ \\
Lewy body dementia & 19 & $10.2(0.92-14.2)$ \\
Unspecified cases & 85 & $45.5(39.4-55.6)$ \\
Prevalence of depression among persons with dementia according to the type of \\
dementia \\
$\quad$
\end{tabular}

As regards, the comorbidities of the diseases that this study population presented at the visiting time in Community Center of Mental Health of Shkodra district look like the following. The majority of patients with dementia reported presence of hypertension as a comorbidity 155/187. In terms of heart diseases, 98/187 of patients had cardiac problems. Hyperlipidemia were referred in 92/187 of patients, diabetes in 94/187, cerebrovascular diseases in 25/187 and current smoker in $109 / 187$ of them
Table 3: Comorbidities diseases among the patients with $A Q 8$ dementia and depression according to the gender

\begin{tabular}{|c|c|c|c|c|c|}
\hline \multirow[t]{2}{*}{ Variables } & \multirow[t]{2}{*}{ Number of cases } & \multicolumn{2}{|c|}{$\begin{array}{l}\text { Dementia } \\
\text { patients (187) }\end{array}$} & \multicolumn{2}{|c|}{$\begin{array}{l}\text { Depression } \\
\text { patients (84) }\end{array}$} \\
\hline & & Women & Men & Women & Men \\
\hline Hypertension & 155 & 86 & 69 & 25 & 29 \\
\hline Heart diseases & 98 & 41 & 57 & 26 & 38 \\
\hline Hyperlipidemia & 92 & 43 & 49 & 21 & 32 \\
\hline Diabetes & 94 & 43 & 51 & 29 & 34 \\
\hline Cerebrovascular diseases & 25 & 11 & 14 & 7 & 10 \\
\hline Current smoker & 109 & 18 & 91 & 11 & 56 \\
\hline
\end{tabular}

In Table 3 are scientifically presented comorbidities diseases of patients with dementia and depression according to the gender (women-men). As observed, hypertension was more predominant in females with dementia compared to the males. Oppositely, patients with depression appears a different situation, where the males are more predominant compared to females.

While as to the rest of comorbidities was seen the predominance of males compared to females in both patients with depression and dementia. In addition, the same situation arises for current smoker, males are more predominant versus females.

In terms of patients with dementia appears a higher number of cases in males compared to females, but in patients with depression appears the opposite, so is a predominance of females compared to males. Based on multiple regression analysis used to identify factors predicting severity of depression in this study, is found a strong association for the gender. Females were 2.9 (odds ratio) time in risk to develop depression compared to males $95 \% \mathrm{Cl}(1.6-5.4) \mathrm{p}=0.0005$ (Table 4).

According to the marital status, patients that referred being single, widowed, or divorced were grouped in the non-married group and in other group are all married patients. There is an association between marital status and patients in depression. Non married dementia's patients resulted 1.78 times in risk to developed depression compared to the married dementia's patients for $\mathrm{Cl} 95 \%(1.00-3.22) \mathrm{p}=0.05$.

The analysis related to type of residence, shows a strong association among those living in rural areas compared to those living in urban areas. Patients with dementia living in rural areas resulted 2.9 times in risk to developed depression compared to those living in urban areas, for Cl 95\% p $=0.0011$.

Regarding the lifestyle of dementia patients, most of them lived with their family, however, there was a strong association among dementia patients living alone and those who lived with their family. Dementia patients with depression living alone resulted 4.9 times in risk to developed depression compared to those living with their family for $\mathrm{Cl} 95 \%$ (2.39-10.2) $p<0.0001$. There is no association between the age and education level among the patient with dementia and depression. In two cases, the $p$ value resulted $>0.05$ (Table 4). 
Table 4: Risk of depression associated with dementia

\begin{tabular}{|c|c|c|c|c|c|}
\hline Characteristics & Total number & Depression & No depression & OR $(95 \% \mathrm{Cl})$ & $\mathrm{p}$-value \\
\hline \multicolumn{6}{|l|}{ Gender } \\
\hline Men & 113 & 39 & 74 & 1 reference & \\
\hline Women & 74 & 45 & 29 & $2.94(1.60-5.40)$ & 0.0005 \\
\hline \multicolumn{6}{|l|}{ Age groups } \\
\hline Less than 70 years old & 12 & 6 & 6 & 1 reference & \\
\hline More than 70 years old & 175 & 78 & 97 & $1.24(1.60-5.40)$ & 0.7 \\
\hline \multicolumn{6}{|l|}{ Type of residence } \\
\hline Urban & 126 & 46 & 80 & 1 reference & \\
\hline Rural & 61 & 38 & 23 & $2.9(1.53-5.5)$ & 0.0011 \\
\hline \multicolumn{6}{|l|}{ Marital status } \\
\hline Married & 108 & 42 & 66 & 1 reference & \\
\hline No married (single, divorced, widow) & 79 & 42 & 37 & $1.78(1.00-3.22)$ & 0.05 \\
\hline \multicolumn{6}{|l|}{ Lifestyle } \\
\hline Living with family & 139 & 49 & 90 & 1 reference & \\
\hline Living alone & 48 & 35 & 13 & $4.9(2.39-10.2)$ & $<0.0001$ \\
\hline \multicolumn{6}{|l|}{ Education level } \\
\hline Without or low education level & 54 & 31 & 23 & $1.54(0.62-3.78)$ & 0.3 \\
\hline Moderate level & 104 & 39 & 65 & $1.47(0.64-3.3)$ & 0,36 \\
\hline High level & 30 & 14 & 16 & 1 reference & \\
\hline
\end{tabular}

\section{Discussion}

In terms of depressive symptoms, they are more prevalent in the elderly. Moreover, depression is more prevalent among people with dementia. Depressive symptoms have been noted to occur in approximately $20-30 \%$ of people with dementia. Sustained and disabling major depressive episodes are more common in those with dementia than in age-matched controls without dementia [6]. This scientific study highlights the prevalence depression in elderly people with dementia and assesses the association between them and risk factors. The prevalence of depression among the elderly with dementia resulted $44.9 \%$. This prevalence turned out to be more or less the same as another study conducted by Ferri et al. [9] who reported that depressive symptoms were found in $43.8 \%$ of the persons with dementia. Reversing it, this study for the case in question among dementia patients resulted higher compared to the study of Andreasen et al. [10] who found the prevalence rate of depression among older adults with dementia living in low- and middle-income countries $12.4 \%$. However, prevalence estimation of depression in dementia population varies greatly across studies, and also, study populations and definition of dementia vary among the studies and the results are not fully comparable [10].

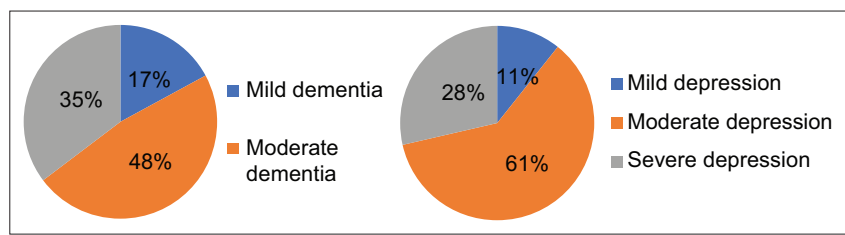

Figure 1: Severity of dementia and depression in the study population

Age is the primary risk factor for developing dementia (strong scientific evidence). Rising life expectancies are increasing the number of people who develop dementia disorders. Approximately $1 \%$ of 65 years old and more than $50 \%$ of 90 years old have a dementia disorder [11]. Furthermore, Andreasen et al. in his study found that the gender-specific risk of depression associated with dementia was higher for males than females [10]. A further study reported that age, severity of depression, race, education, and vascular risk factors have been noted to make significant contributions to dementia and especially to late-onset depression [12].

In this study, the majority of patients were over 70 years old, most of them with dementia turned out to be males. Concerning patients with depression within patients with dementia, the most predominant gender were female compared to males. There is no association between the age and depression among people with dementia. Furthermore, there is a strong association between risk factors for depression among patients with dementia is consistent with most cohort studies [13], [14], [15], [16], [17], [18], [19]. As a result, there is an association for risk factor such as gender, type of residence, marital status, and lifestyle. For all the cases in question risks factor, the $p$ value resulted $<0.05$.

The diagnostic criteria for depression among patients with dementia have varied considerably among studies and many researchers have failed to quantify participants' severity of depression [20]. This study shows a predominance of moderate dementia $48 \%$ and in the same time predominance in moderate depression among patients $61 \%$.

Individuals with dementia are likely to become depressed and among the dementing disorders, LBD carries the highest risk for depression [21], [22]. The incidence of depression may be $30 \%$ in vascular dementia and in Alzheimer's disease [23]. This study shows in detail the prevalence of type of dementia among patients. The prevalence for $A D$ resulted $31.5 \%$, for VD, prevalence was $12.8 \%$, and for LBD $10.2 \%$. Furthermore, $45.5 \%$ of all patients were classified in unspecified cases.

Humans with dementia suffer from a high prevalence of concurrent medical conditions known as comorbidities [24]. Research establishes that the prevalence of comorbid conditions in persons with dementia is high [25]. Studies, for instance, have estimated that $61 \%$ of people with Alzheimer's disease have three or more comorbid diagnoses [26]. Many studies reported that as the severity of the dementia 
increases, so does the rate of comorbid conditions [23], [27]. The cardiovascular health study found a cumulative prevalence of $26 \%$ for depression among individuals with mild cognitive impairment $\mathrm{MCl}$ [28]. In the opposite way, investigators of the Italian Longitudinal Study on Aging found depressive symptoms in $63 \%$ of the patients with $\mathrm{MCl}$ [29]. Majority of patients who display dementia in this study reported the presence of hypertension as a comorbidity. Comorbidities such as heart diseases, hyperlipidemia, diabetes, and cerebrovascular diseases were identified also. Hypertension was more predominant in females who pose dementia and a different situation for patients with depression, in which males are more predominant to females.

Remaining number of comorbidities was seen a predominance in males compared to females, in both patients with depression even to those who display dementia. It is also worth noting that the same situations arise for current smoker, males are more predominant versus females.

\section{Conclusion}

Depression in older adults is a serious concern, especially in dementia population, which often is underdiagnosed being masked by cognitive impairments. Prevalence estimates of depression in dementia population vary greatly across studies, and a reliable result is crucial for further interventions. The findings highlight a high prevalence of depression within the dementia patients. There is found a strong association between depression and gender, lifestyle, type, or residence of the patients who present dementia. The prevalence of comorbid conditions in individuals who display dementia is high. While comorbidities are often treatable and some may be reversible, the focus on dementia as a condition in isolation, both in public policy and in medical practice, risks comorbidities remaining undiagnosed, potentially reducing people's quality of life, and leading to early mortality. Knowledge in the interactions between the depression and dementia will likely contribute to the timely prevention, identification, and treatment of depression in the elderly and will influence on their quality of life.

\section{Limitation}

Although all of the baseline and nearly all of the subsequent neuropsychological assessments were performed by a specialized medical staff, this study presents a limitation, because, we record a low figure of patients and some findings according to the risk factor for dementia and depression have not resulted significant.

\section{References}

1. Livingston G, Sommerlad A, Orgeta V, Costafreda SG, Huntley J, Ames $\mathrm{D}$, et al. Dementia prevention, intervention, and care. Lancet. 2017;390(10113):2673-34. https://doi.org/10.1016/ S0140-6736(17)31363-6

PMid:28735855

2. Alzheimer's Disease International. Policy Brief for G8 Heads of Government. The Global Impact of Dementia 2013-2050. London: Alzheimer's Disease International; 2013.

3. Muliyala KP, Varghese $M$. The complex relationship between depression and dementia. Ann Indian Acad Neurol. 2010;13(2):S69-73. https://doi.org/10.4103/0972-2327.74248 PMid:21369421

4. Asmer MS, Kirkham J, Newton $\mathrm{H}$, Ismail Z, Elbayoumi $\mathrm{H}$, Leung $\mathrm{RH}$, et al. Meta-analysis of the prevalence of major depressive disorder among older adults with dementia. J Clin Psychiatry 2018;79:17r11772. https://doi.org/10.4088/ JCP.17r11772

PMid:30085437

5. Kubo Y, Hayashi H, Kozawa S, Okada S. Relevant factors of depression in dementia modifiable by non-pharmacotherapy: A systematic review. Psychogeriatrics. 2019;19(2):181-91. https://doi.org/10.1111/psyg.12371 PMid:30246316

6. Kitching D. Depression in dementia. Aust Prescr. 2015;38(6):209-2011. https://doi.org/10.18773/austprescr.2015.071 PMid:26843714

7. Arias-Merino ED, Mendoza-Ruvalcaba NM, Ortiz GG, Velázquez-Brizuela IE, Meda-Lara RM, Cueva-Contreras J. Physical function and associated factors in communitydwelling elderly people in Jalisco, Mexico. Arch Gerontol Geriatr. 2012;54(3):e271-8. https://doi.org/10.1016/j. archger.2012.02.010

PMid:22440759

8. Arimany-Manso J, Gómez-Durán EL, Boada M, Mas SV Research in incapacity proceedings concerning people with neurodegenerative diseases that cause dementia. Rev Española Med Legal. 2012;38:89-90.

9. Ferri CP, Ames D, Prince M. 10/66 Dementia Research Group. Behavioral and psychological symptoms of dementia in developing countries. Int Psychogeriatr. 2004;16(4):441-59. https://doi.org/10.1017/s1041610204000833

PMid: 15715360

10. Andreasen P, Lönnroos E, von Euler-Chelpin MC. Prevalence of depression among older adults with dementia living in low-and middle-income countries: A cross-sectional study. Eur J Public Health. 2014;24(1):40-4. https://doi.org/10.1093/eurpub/ckt014 PMid:23417621

11. Swedish Council on Health Technology Assessment. DementiaCaring, Ethics, Ethnical and Economical Aspects: A Systematic Review. Stockholm: Swedish Council on Health Technology Assessment (SBU); 2008.

12. Sheline YI, Barch DM, Garcia K, Gersing K, Pieper C, WelshBohmer $\mathrm{K}$, et al. Cognitive function in late life depression: Relationships to depression severity, cerebrovascular risk factors and processing speed. Biol Psychiatry.2006;60:58-65. https://doi.org/10.1016/j.biopsych.2005.09.019 PMid:16414031

13. Li G, Wang LY, Shofer JB, Thompson ML, Peskind ER, McCormick W, et al. Temporal relationship between depression and dementia: Findings from a large community-based 15-year follow-up study. Arch Gen Psychiatry. 2011;68(9):970-7. https:// doi.org/10.1001/archgenpsychiatry.2011.86 


\section{PMid:21893662}

14. Wilson RS, Barnes LL, de Leon CF, Aggarwal NT, Schneider JS, Bach J, et al. Depressive symptoms, cognitive decline, and risk of AD in older persons. Neurology. 2002;59(3):364-70. https:// doi.org/10.1212/wnl.59.3.364

PMid:12177369

15. Barnes DE, Alexopoulos GS, Lopez OL, Williamson JD, Yaffe K. Depressive symptoms, vascular disease, and mild cognitive impairment: Findings from the cardiovascular health study. Arch Gen Psychiatry. 2006;63(3):273-9. https://doi.org/10.1001/ archpsyc.63.3.273

PMid:16520432

16. Irie $\mathrm{F}$, Masaki $\mathrm{KH}$, Petrovitch $\mathrm{H}$, Abbott RD, Ross GW, Taaffe DR, et al. Apolipoprotein $E \varepsilon 4$ allele genotype and the effect of depressive symptoms on the risk of dementia in men: The Honolulu-Asia Aging study. Arch Gen Psychiatry. 2008;65(8):906-12. https://doi.org/10.1001/archpsyc.65.8.906 PMid: 18678795

17. Luchsinger JA, Honig LS, Tang MX, Devanand DP. Depressive symptoms, vascular risk factors, and Alzheimer's disease. Int J Geriatr Psychiatry. 2008;23(9):922-8. https://doi.org/10.1002/ gps.2006

PMid: 18327871

18. Saczynski JS, Beiser A, Seshadri S, Auerbach S, Wolf PA, Au R Depressive symptoms and risk of dementia: The Framingham Heart Study. Neurology. 2010;75(1):35-41. https://doi. org/10.1212/WNL.0b013e3181e62138

PMid:20603483

19. Dotson VM, Beydoun MA, Zonderman AB. Recurrent depressive symptoms and the incidence of dementia and mild cognitive impairment. Neurology. 2010;75(1):27-34. https://doi. org/10.1212/WNL.0b013e3181e62124

PMid:20603482

20. Rohling ML, Green P, Allen LM 3rd, Iverson GL. Depressive symptoms and neurocognitive test scores in patients passing symptomvaliditytests.Arch ClinNeuropsychol.2002;17(3):205-22. https://doi.org/10.1016/S0887-6177(01)00109-3

PMid: 14589724

21. Tsopelas C, Stewart R, Savva GM, Brayne C, Ince P, Thomas A, et al. Neuropathological correlates of late-life depression in older people. Br J Psychiatry. 2011;198(2):109-14. https://doi. org/10.1192/bjp.bp.110.078816

PMid:21282780

22. Enache D, Winblad B, Aarsland D. Depression in dementia: Epidemiology, mechanisms, and treatment. Curr Opin Psychiatry. 2011;24:461-72. https://doi.org/10.1097/YCO.0b013e32834bb9d4 PMid:21926624

23. Aimee WK, Racine CA, Quitania LC, Kramer JH, Christine CW, Miller BL. Cognitive and neuropsychiatric profile of the synucleinopathies: Parkinson disease, dementia with Lewy bodies and multiple system atrophy. Alzheimer Dis Assoc Disord. 2009;23(4):365-70. https://doi.org/10.1097/ WAD.0b013e3181b5065d PMid: 19935145

24. Scrutton J, Brancati CU. Dementia and Comorbidities: Ensuring Parity of Care, Report, UK; 2016. p. 10.

25. Bunn F, Burn AM, Goodman C, Rait G, Norton S, Robinson L, et al. Comorbidity and dementia: A scoping review of the literature. BMC Med. 2014;12:192. https://doi.org/10.1186/ s12916-014-0192-4

PMid:25358236

26. Fillit HM The pharmacoeconomics of Alzheimer's disease. Am J Manag Care. 2000;6 Suppl 22:S1139-44; discussion S1145-8. PMid: 11142178

27. Doraiswamy PM, Leon J, Cummings JL, Marin D, Neumann PJ. Prevalence and impact of medical comorbidity in Alzheimer's disease. J Gerontol A Biol Sci Med Sci. 2002;57(3):M173-7. https://doi.org/10.1093/gerona/57.3.m173 PMid:11867654

28. Lyketsos CG, Lopez O, Jones B, Fitzpatrick AL, Breitner J, DeKosky S. Prevalence of neuropsychiatric symptoms in dementia and mild cognitive impairment: Results from the cardiovascular health study. JAMA. 2002;288(12):1475-83. https://doi.org/10.1001/jama.288.12.1475

PMid: 12243634

29. Solfrizzi V, D'Introno A, Colacicco AM, Capurso C, Del Parigi A, Caselli RJ, et al. Incident occurrence of depressive symptoms among patients with mild cognitive impairment-the Italian longitudinal study on aging. Dement Geriatr Cogn Disord. 2007;24(1):55-64. https://doi.org/10.1159/000103632 PMid: 17565214 